\title{
Research Article \\ Complex Dynamics in a Nonlinear Cobweb Model for Real Estate Market
}

\author{
Junhai Ma and Lingling $\mathrm{Mu}$
}

Received 10 October 2006; Revised 1 April 2007; Accepted 2 July 2007

We establish a nonlinear real estate model based on cobweb theory, where the demand function and supply function are quadratic. The stability conditions of the equilibrium are discussed. We demonstrate that as some parameters varied, the stability of Nash equilibrium is lost through period-doubling bifurcation. The chaotic features are justified numerically via computing maximal Lyapunov exponents and sensitive dependence on initial conditions. The delayed feedback control (DFC) method is applied to control the chaos of system.

Copyright $\odot 2007 \mathrm{~J}$. Ma and L. Mu. This is an open access article distributed under the Creative Commons Attribution License, which permits unrestricted use, distribution, and reproduction in any medium, provided the original work is properly cited.

\section{Introduction}

Cobweb models describe the price dynamics in a market of a nonstorable good that takes one time unit to produce [1]. In economic modeling, many examples of cobweb chaos have been demonstrated. Some of the most famous examples include [2-9]. Hommes [5] applies the concept of adaptive expectations in a cobweb model with a single producer to investigate the occurrence of strange and chaotic behavior. Finkenstädt [3] applied linear supply and nonlinear demand functions. Hommes [4] and Jensen and Urban [6] used linear demand functions with nonlinear supply equations. These findings indicate that the nonlinear cobweb model may explain various irregular fluctuations observed in real economic data. In this study, we go one step further to study the cobweb model with nonlinear demand and supply function. A possible source of such an evolutionary market dynamics is an interaction between government and real estate developer.

Traditional cobweb models usually describe a dynamic price adjustment in agricultural markets with a supply response lag [2]. Consider, for instance, the supply of housing. The time of housing construction guarantees a finite lag between the time the production 
decision is made and the time the housing is ready for sale. The real estate developer's decision about how many houses should be built and sale is usually based on current and past experience. This principle is the same as that of agricultural product. So it is feasible to introduce cobweb model into real estate market.

The present paper attempts to establish a nonlinear model for the real estate market, and introduce adjustment parameters of housing price and land price into the model, which can denote the game behavior of players. The system stability with the variation of parameters is analyzed. Numerical simulations verify the complexity of system evolvement. Finally, time-delayed feedback control method is used to keep the system from chaos and bifurcation.

\section{Nonlinear models for real estate market}

In this paper we assume that all real estate developers in the market are belong to one benefit group and have a common benefit target. Usually the price $p$ is characterized by the nonlinear inverse demand function of $p=a-b \sqrt{Q}$, where $a$ and $b$ are positive constants, $a$ is the maximum price in the market, and $Q$ is the total quantity in the market. This kind of form has been used in other oligopoly models and in the experimental economics dealing with learning and expectations formation (see, e.g., [10-12]). The transformation of this formula is as follows:

$$
D_{1}(t)=b_{0}-b_{1} p_{1}(t)+b_{2} p_{1}^{2}(t), \quad D_{2}(t)=c_{0}-c_{1} p_{2}(t)+c_{2} p_{2}^{2}(t)
$$

where $b_{0}, b_{1}, b_{2}, c_{0}, c_{1}, c_{2}$ are positive constants, $p_{1}(t)$ is the land price at time period $t$, $p_{2}(t)$ is the housing price at time period $t, D_{1}(t)$ is the land demand at time period $t$, and $D_{2}(t)$ is the housing demand at time period $t$. Due to the law of demand that the slope of demand curve is negative, the prices $p_{1}(t)$ and $p_{2}(t)$ must, respectively, satisfy the inequalies: $2 b_{2} p_{1}(t)-b_{1}<0$ and $2 c_{2} p_{2}(t)-c_{1}<0 ; 4 b_{2} b_{0}-b_{1}^{2}>0,4 c_{2} c_{0}-c_{1}^{2}>0$ must hold, thus the signs of demand equations in formula (2.1) are positive.

In this case, the land market and housing market are interrelated. Though the housing market does not directly affect land market, the land price impacts the housing supply which decreases with increasing land price. This rule is the same as that of hog and corn as stated by Waugh [13]. Real estate companies adjust the housing supply according to the relative policies and the situation of housing price and land price. The formula of supply can be supposed as follows:

$$
S_{1}(t)=e_{0}+e_{1} p_{1}(t)+e_{2} p_{1}^{2}(t), \quad S_{2}(t)=d_{0}+d_{1} p_{2}(t)+d_{2} p_{2}^{2}(t)-d_{3} p_{1}(t),
$$

where $d_{0}, d_{1}, d_{2}, d_{3}, e_{0}, e_{1}, e_{2}$ are positive constants, $S_{1}(t)$ is the land supply at time period $t$, and $S_{2}(t)$ is the housing supply at time period $t$. Because $2 e_{2} p_{1}(t)+e_{1}>0$ and $2 d_{2} p_{2}(t)+$ $d_{1}>0$, so we can affirm that the slope of supply curve is positive, and it is in accordance with the law of supply. Providers begin to supply the products only when

$$
p_{1}(t)>\frac{-e_{1}+\sqrt{e_{1}^{2}-4 e_{2} e_{0}}}{2 e_{2}}, \quad p_{2}(t)>\frac{-d_{1}+\sqrt{d_{1}^{2}-4 d_{2} d_{0}}}{2 d_{2}} .
$$


Define

$$
Z(p)=D(p)-S(p)
$$

$Z(p)$ is excess demand function descending with price, which denotes the gap between demand and supply. When the price is low, excess demand exists and when the price is high, excess supply exists, thus $p^{*}$ that satisfies the equation $Z\left(p^{*}\right)=0$ is called equilibrium point.

Substituting (2.1) and (2.2) into (2.4), we obtain

$$
\begin{aligned}
& Z\left(p_{1}(t)\right)=b_{0}-e_{0}-\left(e_{1}+b_{1}\right) p_{1}(t)+\left(b_{2}-e_{2}\right) p_{1}^{2}(t) \\
& Z\left(p_{2}(t)\right)=c_{0}-d_{0}-\left(d_{1}+c_{1}\right) p_{2}(t)+\left(c_{2}-d_{2}\right) p_{2}^{2}(t)+d_{3} p_{1}(t), \quad t=0,1,2, \ldots
\end{aligned}
$$

Since $Z(p)$ follows the law of demand, the following conditions must hold:

$$
\begin{gathered}
b_{2}-e_{2}>0, \\
c_{2}-d_{2}>0, \\
2\left(c_{2}-d_{2}\right) p_{2}(t)-\left(d_{1}+c_{1}\right)<0, \\
2\left(b_{2}-e_{2}\right) p_{1}(t)-\left(e_{1}+b_{1}\right)<0 .
\end{gathered}
$$

$\alpha_{1}$ is the adjustment parameter of land price, which denotes the adjustment degree of benchmark land price controlled by government through the land supply plan. $\alpha_{2}$ is the adjustment parameter of housing price, the dynamic model of land price and housing price can be established as follows:

$$
\begin{aligned}
& p_{1}(t)=p_{1}(t-1)+\alpha_{1} Z\left(p_{1}(t-1)\right), \\
& p_{2}(t)=p_{2}(t-1)+\alpha_{2} Z\left(p_{2}(t-1)\right),
\end{aligned} \quad t=0,1,2, \ldots,
$$

where $\alpha_{1}$ and $\alpha_{2}$ are positive parameters.

It is clear that the excess functions of land and housing with adjustment parameters are two-dimensional nonlinear map, which can be regarded as a discrete dynamic system.

\section{Stability analysis}

3.1. Bifurcation and chaos. Expansion formula of (2.7)is:

$$
\begin{aligned}
& p_{1}(t)=p_{1}(t-1)+\alpha_{1}\left\{b_{0}-e_{0}-\left(e_{1}+b_{1}\right) p_{1}(t-1)+\left(b_{2}-e_{2}\right) p_{1}^{2}(t-1)\right\}, \\
& p_{2}(t)=p_{2}(t-1)+\alpha_{2}\left\{c_{0}-d_{0}-\left(d_{1}+c_{1}\right) p_{2}(t-1)+\left(c_{2}-d_{2}\right) p_{2}^{2}(t-1)+d_{3} p_{1}(t-1)\right\},
\end{aligned}
$$

Let

$$
\begin{gathered}
u=\frac{\alpha_{1}\left(e_{2}-b_{2}\right)}{1+\alpha_{1} \sqrt{\left(e_{1}+b_{1}\right)^{2}-4\left(e_{0}-b_{0}\right)\left(e_{2}-b_{2}\right)}} \\
U=\frac{1}{2}-\frac{1}{2} \cdot \frac{1-\alpha_{1}\left(e_{1}+b_{1}\right)}{1+\alpha_{1} \sqrt{\left(e_{1}+b_{1}\right)^{2}-4\left(e_{2}-b_{2}\right)\left(e_{0}-b_{0}\right)}}, \quad x(t)=u p_{1}(t)+U .
\end{gathered}
$$


The transform of the first equation in formula (3.1) is:

$$
x(t)=\lambda x(t-1)(1-x(t-1))
$$

where $\lambda=1+\alpha_{1} \sqrt{\left(e_{1}+b_{1}\right)^{2}-4\left(e_{2}-b_{2}\right)\left(e_{0}-b_{0}\right)}$. The stability of $x(t)$ varies along with variety of $\lambda$ according to Logistic rule.

If $\alpha_{1}<0$, then $\lambda<1$ implies that one fixed point exists in system (3.1), however, $\alpha_{1}<0$ is insignificant, so we do not give consideration.

If $0 \leq \alpha_{1}<2 / \sqrt{\left(e_{1}+b_{1}\right)^{2}-4\left(e_{2}-b_{2}\right)\left(e_{0}-b_{0}\right)}$, then $1 \leq \lambda<3$ implies that two fixed points exist in system (3.1) and bifurcation appears.

If $2 / \sqrt{\left(e_{1}+b_{1}\right)^{2}-4\left(e_{2}-b_{2}\right)\left(e_{0}-b_{0}\right)} \leq \alpha_{1} \leq \sqrt{6} / \sqrt{\left(e_{1}+b_{1}\right)^{2}-4\left(e_{2}-b_{2}\right)\left(e_{0}-b_{0}\right)}$, then $3 \leq \lambda \leq 1+\sqrt{6}$ implies that four fixed points exist in system (3.1) and period-doubling bifurcation appears.

As $\lambda$ increases, the number of fixed points continues to grow until $\lambda=3.5699$; when $\alpha_{1}=2.5699 / \sqrt{\left(e_{1}+b_{1}\right)^{2}-4\left(e_{2}-b_{2}\right)\left(e_{0}-b_{0}\right)}$, the value of $x(t)$ is unequal to any point that appeared before, system enters chaos from period doubling bifurcation.

The same argument holds for the second equation in formula (3.1). Let $\alpha_{1}=0$ :

When $0<\alpha_{2}<2 / \sqrt{\left(d_{1}+c_{1}\right)^{2}-4\left(d_{0}-c_{0}\right)\left(d_{2}-c_{2}\right)}$, bifurcation occurs.

When $2 / \sqrt{\left(d_{1}+c_{1}\right)^{2}-4\left(d_{0}-c_{0}\right)\left(d_{2}-c_{2}\right)} \leq \alpha_{2} \leq \sqrt{6} / \sqrt{\left(d_{1}+c_{1}\right)^{2}-4\left(d_{0}-c_{0}\right)\left(d_{2}-c_{2}\right)}$, period doubling bifurcation occurs.

When $\alpha_{2}=2.5699 / \sqrt{\left(d_{1}+c_{1}\right)^{2}-4\left(d_{0}-c_{0}\right)\left(d_{2}-c_{2}\right)}$, system enters chaotic state from period doubling bifurcation.

3.2. Stability analysis. Now we discuss the stability of fixed points of the discrete dynamic system (3.1) through analyzing the eigenvalues of asymptotic linear equation of formula (3.1).

Four fixed points of difference function (3.1) are obtained:

$$
E:\left\{\begin{array}{l}
p_{1}=\frac{b_{1}+e_{1} \pm \sqrt{\left(b_{1}+e_{1}\right)^{2}-4\left(e_{2}-b_{2}\right)\left(e_{0}-b_{0}\right)}}{2\left(b_{2}-e_{2}\right)}, \\
p_{2}=\frac{d_{1}+c_{1} \pm \sqrt{\left(d_{1}+c_{1}\right)^{2}-4\left(c_{2}-d_{2}\right)\left(c_{0}-d_{0}+d_{3} p_{1}\right)}}{2\left(c_{2}-d_{2}\right)},
\end{array}\right.
$$

provided that:

$$
\begin{gathered}
\left(b_{1}+e_{1}\right)^{2}-4\left(e_{2}-b_{2}\right)\left(e_{0}-b_{0}\right) \geq 0, \\
\left(d_{1}+c_{1}\right)^{2}-4\left(c_{2}-d_{2}\right)\left(c_{0}-d_{0}+d_{3} p_{1}\right) \geq 0 .
\end{gathered}
$$


LEMma 3.1. The equilibrium

$$
E_{1}\left(\frac{b_{1}+e_{1}+\sqrt{\left(b_{1}+e_{1}\right)^{2}-4\left(e_{2}-b_{2}\right)\left(e_{0}-b_{0}\right)}}{2\left(b_{2}-e_{2}\right)}, \frac{d_{1}+c_{1}+\sqrt{\left(d_{1}+c_{1}\right)^{2}-4\left(c_{2}-d_{2}\right)\left(c_{0}-d_{0}+d_{3} p_{1}\right)}}{2\left(c_{2}-d_{2}\right)}\right)
$$

is an unstable equilibrium point.

Proof. In order to prove this result, we find the eigenvalues of the Jacobian matrix $J$. In fact at $E_{1}$, the Jacobian matrix becomes a triangular matrix:

$J\left(E_{1}\right)$

$$
=\left[\begin{array}{cc}
1+\alpha_{1}\left[\left(b_{1}+e_{1}\right)^{2}-4\left(e_{2}-b_{2}\right)\left(e_{0}-b_{0}\right)\right]^{1 / 2} & 0 \\
\alpha_{2} d_{3} & 1+\alpha_{2}\left[\left(d_{1}+c_{1}\right)^{2}-4\left(c_{2}-d_{2}\right)\left(c_{0}-d_{0}+d_{3} p_{1}\right)\right]^{1 / 2}
\end{array}\right]
$$

whose eigenvalues are given by the diagonal entries. They are:

$$
\begin{gathered}
\lambda_{1}=1+\alpha_{1}\left[\left(b_{1}+e_{1}\right)^{2}-4\left(e_{2}-b_{2}\right)\left(e_{0}-b_{0}\right)\right]^{1 / 2}, \\
\lambda_{2}=1+\alpha_{2}\left[\left(d_{1}+c_{1}\right)^{2}-4\left(c_{2}-d_{2}\right)\left(c_{0}-d_{0}+d_{3} p_{1}\right)\right]^{1 / 2} .
\end{gathered}
$$

It is clear that when condition (3.5) holds, then $\left|\lambda_{1}\right|>1$ and $\left|\lambda_{2}\right|>1$. Then $E_{1}$ is an unstable equilibrium point of the system (3.1). This completes the proof of the proposition.

The stability of other points can also be judged by the above method.

3.3. The stable region of equilibrium point. In this subsection, we analyze the asymptotic stability of the equilibrium point for the two-dimensional map (3.1). We determine the region of stability in the plane of the parameters $\left(\alpha_{1}, \alpha_{2}\right)$. The Jacobian matrix at $E^{*}\left(p_{1}^{*}(t), p_{2}^{*}(t)\right)$ takes the form

$$
J=\left[\begin{array}{cc}
1-\alpha_{1}\left(e_{1}+b_{1}\right)+2 \alpha_{1}\left(b_{2}-e_{2}\right) p_{1} *(t) & 0 \\
\alpha_{2} d_{3} & 1-\alpha_{2}\left(d_{1}+c_{1}\right)+2 \alpha_{2}\left(c_{2}-d_{2}\right) p_{2} *(t)
\end{array}\right] .
$$

The characteristic equation of the matrix (3.9) has the form

$$
F(\lambda)=\lambda^{2}-\operatorname{Tr} \lambda+\operatorname{Det}=0
$$

where "Tr" is the trace and "Det" is the determinant of the Jacobian matrix (3.9) which are given by

$$
\begin{aligned}
\operatorname{Tr}= & 2-\alpha_{1}\left(e_{1}+b_{1}\right)+2 \alpha_{1}\left(b_{2}-e_{2}\right) p_{1}{ }^{*}(t)-\alpha_{2}\left(d_{1}+c_{1}\right)+2 \alpha_{2}\left(c_{2}-d_{2}\right) p_{2}{ }^{*}(t), \\
\operatorname{Det}= & 1-\alpha_{1}\left(e_{1}+b_{1}\right)+2 \alpha_{1}\left(b_{2}-e_{2}\right) p_{1}{ }^{*}(t)-\alpha_{2}\left(d_{1}+c_{1}\right)+2 \alpha_{2}\left(c_{2}-d_{2}\right) p_{2}{ }^{*}(t) \\
& +\left[\alpha_{1}\left(e_{1}+b_{1}\right)-2 \alpha_{1}\left(b_{2}-e_{2}\right) p_{1}{ }^{*}(t)\right]\left[\alpha_{2}\left(d_{1}+c_{1}\right)-2 \alpha_{2}\left(c_{2}-d_{2}\right) p_{2}{ }^{*}(t)\right] .
\end{aligned}
$$


Since

$(\operatorname{Tr})^{2}-4 \operatorname{Det}=\left[\alpha_{2}\left(d_{1}+c_{1}\right)-\alpha_{1}\left(e_{1}+b_{1}\right)+2 \alpha_{1}\left(b_{2}-e_{2}\right) p_{1}^{*}(t)-2 \alpha_{2}\left(c_{2}-d_{2}\right) p_{2}^{*}(t)\right]^{2}>0$,

we deduce that the eigenvalues of equilibrium are real. The local stability of equilibrium point is given by Jury's conditions $[14,15]$ which are as follows.

(a) $1-\operatorname{Tr}+\operatorname{Det}>0$.

Lemma 3.2. The condition (a) is always satisfied.

Proof. Because $1-\operatorname{Tr}+$ Det $=\left[\alpha_{1}\left(e_{1}+b_{1}\right)-2 \alpha_{1}\left(b_{2}-e_{2}\right) p_{1} *(t)\right]\left[\alpha_{2}\left(d_{1}+c_{1}\right)-2 \alpha_{2}\left(c_{2}-\right.\right.$ $\left.d_{2}\right) p_{2} *(t)$ ], moreover, the last two conditions in (2.6) are hold, $\alpha_{1}$ and $\alpha_{2}$ are positive parameters, so the sign of " $1-\operatorname{Tr}+$ Det" is positive and the lemma is proven.

(b) $1+\operatorname{Tr}+$ Det $>0$,

$$
\begin{aligned}
1+\operatorname{Tr}+\operatorname{Det}= & 4-2 \alpha_{1}\left(e_{1}+b_{1}\right)+4 \alpha_{1}\left(b_{2}-e_{2}\right) p_{1}^{*}(t)-2 \alpha_{2}\left(d_{1}+c_{1}\right)+4 \alpha_{2}\left(c_{2}-d_{2}\right) p_{2}^{*}(t) \\
& +\left[\alpha_{1}\left(e_{1}+b_{1}\right)-2 \alpha_{1}\left(b_{2}-e_{2}\right) p_{1}^{*}(t)\right]\left[\alpha_{2}\left(d_{1}+c_{1}\right)-2 \alpha_{2}\left(c_{2}-d_{2}\right) p_{2}{ }^{*}(t)\right]
\end{aligned}
$$

(c) Det $-1<0$,

$$
\begin{aligned}
\text { Det }-1= & -\alpha_{1}\left(e_{1}+b_{1}\right)+2 \alpha_{1}\left(b_{2}-e_{2}\right) p_{1}^{*}(t)-\alpha_{2}\left(d_{1}+c_{1}\right)+2 \alpha_{2}\left(c_{2}-d_{2}\right) p_{2}{ }^{*}(t) \\
& +\left[\alpha_{1}\left(e_{1}+b_{1}\right)-2 \alpha_{1}\left(b_{2}-e_{2}\right) p_{1}{ }^{*}(t)\right]\left[\alpha_{2}\left(d_{1}+c_{1}\right)-2 \alpha_{2}\left(c_{2}-d_{2}\right) p_{2}{ }^{*}(t)\right] .
\end{aligned}
$$

The conditions (b) and (c) define a bounded region of stability in the parameters space $\left(\alpha_{1}, \alpha_{2}\right)$. Then the second and third conditions are the conditions for the local stability of equilibrium point which becomes

$$
\begin{aligned}
1+\operatorname{Tr}+\operatorname{Det}= & 4-2 \alpha_{1}\left(e_{1}+b_{1}\right)+4 \alpha_{1}\left(b_{2}-e_{2}\right) p_{1}{ }^{*}(t)-2 \alpha_{2}\left(d_{1}+c_{1}\right)+4 \alpha_{2}\left(c_{2}-d_{2}\right) p_{2}{ }^{*}(t) \\
& +\left[\alpha_{1}\left(e_{1}+b_{1}\right)-2 \alpha_{1}\left(b_{2}-e_{2}\right) p_{1}{ }^{*}(t)\right]\left[\alpha_{2}\left(d_{1}+c_{1}\right)-2 \alpha_{2}\left(c_{2}-d_{2}\right) p_{2}{ }^{*}(t)\right]>0, \\
\text { Det }-1= & -\alpha_{1}\left(e_{1}+b_{1}\right)+2 \alpha_{1}\left(b_{2}-e_{2}\right) p_{1}{ }^{*}(t)-\alpha_{2}\left(d_{1}+c_{1}\right)+2 \alpha_{2}\left(c_{2}-d_{2}\right) p_{2}{ }^{*}(t) \\
& +\left[\alpha_{1}\left(e_{1}+b_{1}\right)-2 \alpha_{1}\left(b_{2}-e_{2}\right) p_{1}^{*}(t)\right]\left[\alpha_{2}\left(d_{1}+c_{1}\right)-2 \alpha_{2}\left(c_{2}-d_{2}\right) p_{2}{ }^{*}(t)\right]<0 .
\end{aligned}
$$

The stability region is bounded by the portion of hyperbola with positive values of $\alpha_{1}$ and $\alpha_{2}$, whose equations are given by the vanishing of the left-hand sides $1+\operatorname{Tr}+\operatorname{Det}=0$ and Det $-1=0$. For the values of $\left(\alpha_{1}, \alpha_{2}\right)$ inside the stability region (see Figure 3.1), the equilibrium point is stable node and loses its stability through a period-doubling bifurcation. The bifurcation curve intersects the axes $\alpha_{1}$ and $\alpha_{2}$, respectively, whose coordinates are given by

$$
A\left(0, \frac{2}{d_{1}+c_{1}-2\left(c_{2}-d_{2}\right) p_{2} *(t)}\right), \quad B\left(\frac{2}{e_{1}+b_{1}-2\left(b_{2}-e_{2}\right) p_{1} *(t)}, 0\right) .
$$




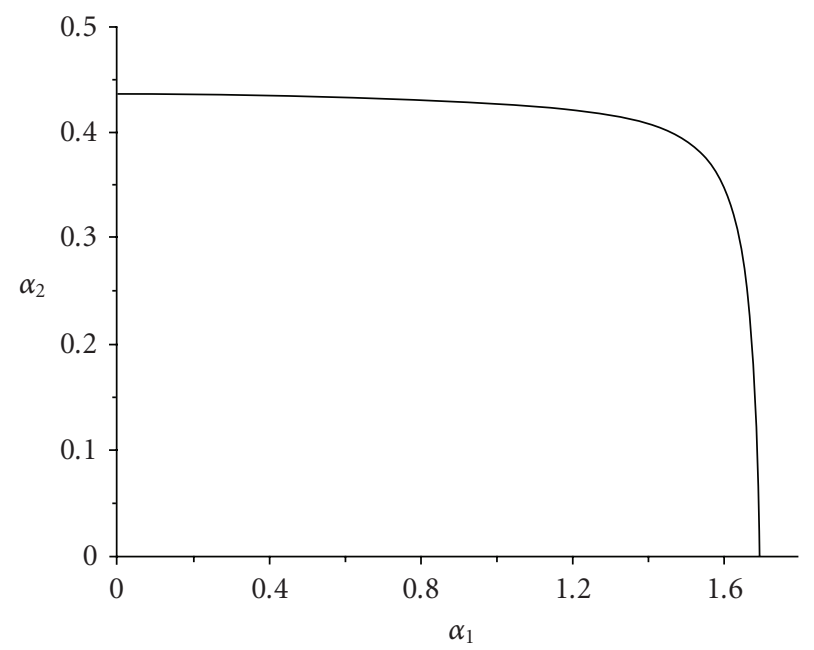

Figure 3.1. Stability region of Nash equilibrium.

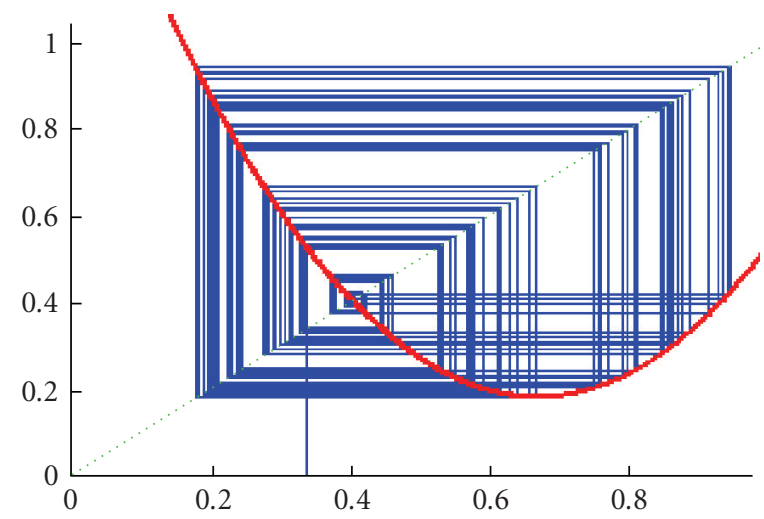

FIgURE 4.1. The graph of map $f_{\alpha_{1}, \alpha_{2}}$.

\section{Numerical simulations}

In order to study the complex dynamics of system (3.1), it is convenient to take the parameters values as follows:

$$
\begin{gathered}
b_{0}=1.2, \quad b_{1}=2, \quad b_{2}=1.6, \quad c_{0}=4, \quad c_{1}=1.6, \quad c_{2}=0.04, \quad d_{0}=0, \\
d_{1}=3, \quad d_{2}=0.02, \quad d_{3}=0.4, \quad e_{0}=0.5, \quad e_{1}=0.3, \quad e_{2}=0.2 .
\end{gathered}
$$

Figure 3.1 shows the region of stability of Nash equilibrium. Equation (3.15) defines the region of stability in the plane of $\left(\alpha_{1}, \alpha_{2}\right)$. Figure 4.1 shows the map of $f_{\alpha_{1}, \alpha_{2}} . x$ coordinate is $p_{1}$ and $y$-coordinate is $f_{\alpha_{1}, \alpha_{2}}\left(p_{1}\right)$. Dynamics of land price in the cobweb model is given by system $p_{1}(t)=f_{\alpha_{1}, \alpha_{2}}\left(p_{1}(t-1)\right)$ with two model parameters. A graphical analysis in Figure 4.1 shows that the map $f_{\alpha_{1}, \alpha_{2}}$ is nonmonotonic with one critical 


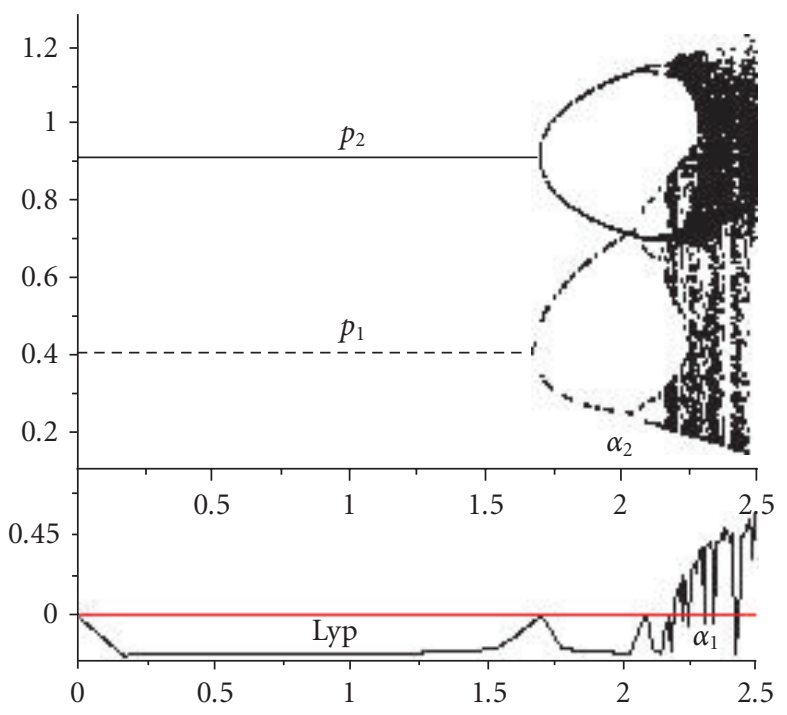

FIgURE 4.2. Bifurcation diagram for $\alpha_{2}=0.4$.

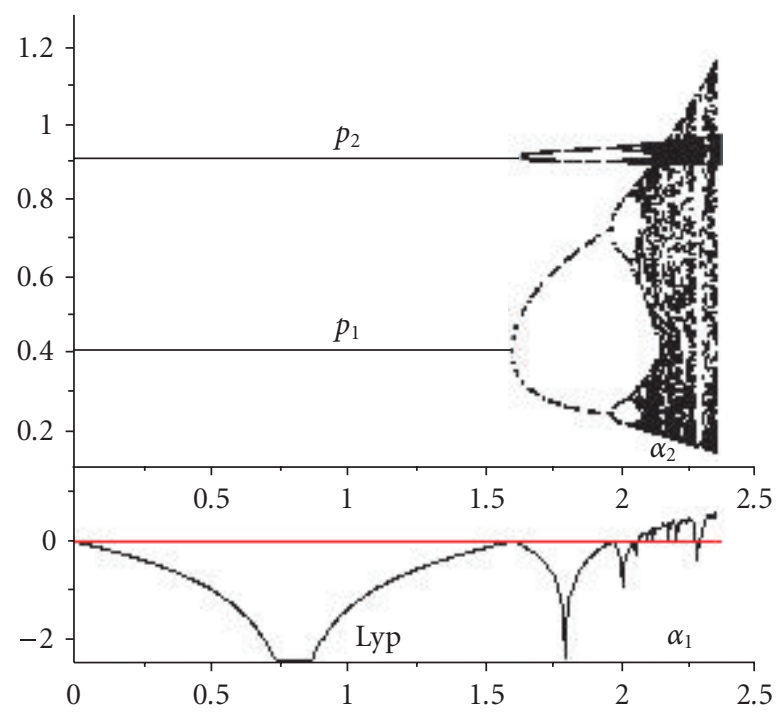

FIgURE 4.3. Bifurcation diagram for $\alpha_{2}=0.2$.

point, where the graph has a (local) minimum, and that initial state $p_{1}(0)=1$ does not converge to a low periodic orbit. Since the graphical analysis in this case does not converge, it suggests that the dynamical behavior is chaotic.

Figures 4.2 and 4.3 show the bifurcation diagrams with respect to the parameter $\alpha_{1}$ and for $\alpha_{2}=0.2$ and 0.4 . In both figures, the Nash equilibrium $E^{*}=(0.4,0.9)$ is locally stable for small values of the parameter $\alpha_{1}$. If $\alpha_{1}$ increases, the Nash equilibrium point 


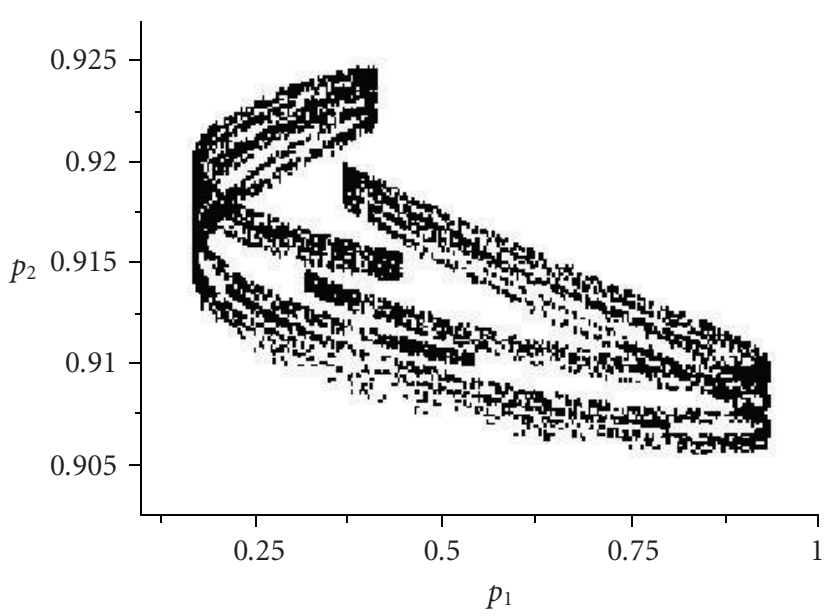

Figure 4.4. Strange attractor for $\alpha_{2}=0.07$.

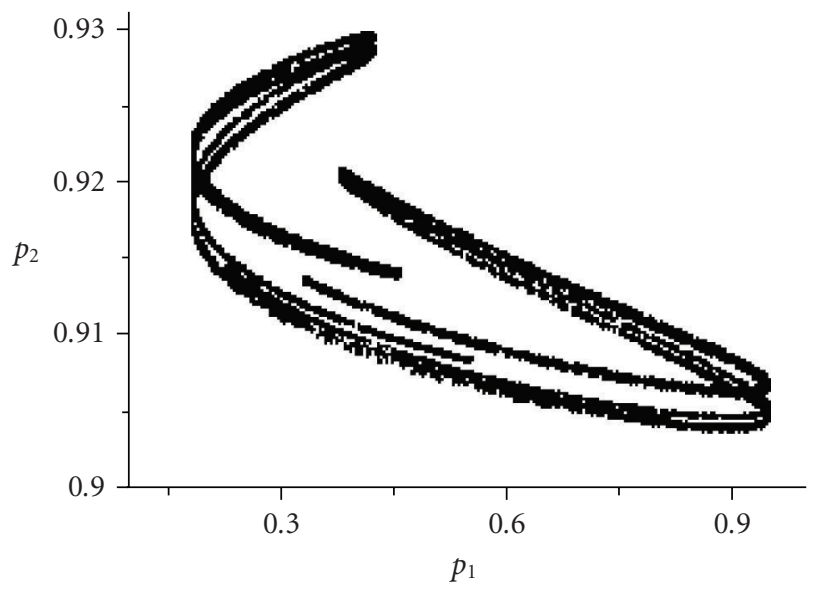

FIGURE 4.5. Strange attractor for $\alpha_{2}=0.1$.

becomes unstable, and one observes complex dynamic behavior occurs such as cycles of higher order and chaos. Also the maximal Lyapunov exponent is plotted in Figures 4.2 and 4.3.

Figures 4.4, 4.5, 4.6, and 4.7 show the graph of strange attractors for the different values of $\alpha_{2}$. The parameter $\alpha_{2}$ takes the values $0.07,0.1,0.2$, and 0.3 , which exhibit fractal structure in both cases.

We compute the difference of two orbits with initial points $\left[p_{1}(0), p_{2}(0)\right]$ and $\left[p_{1}(0)+\right.$ $\left.0.0001, p_{2}(0)\right]$, as well as $\left[p_{1}(0), p_{2}(0)\right]$ and $\left[p_{1}(0), p_{2}(0)+0.0001\right]$, to demonstrate the sensitivity to initial conditions of the system (3.1). The parameters take the values $\left(\alpha_{1}, \alpha_{2}\right)$ $=(2.3,0.6)$ and $\left[p_{1}(0), p_{2}(0)\right]=(1,2)$. The results are shown in Figures 4.8 and 4.9 , where $\Delta p_{1}(t)=p_{1}(t)-p_{1}^{\prime}(t)$ and $p_{1}^{\prime}(t)$ is the value of land price at time period $t$ with initial 


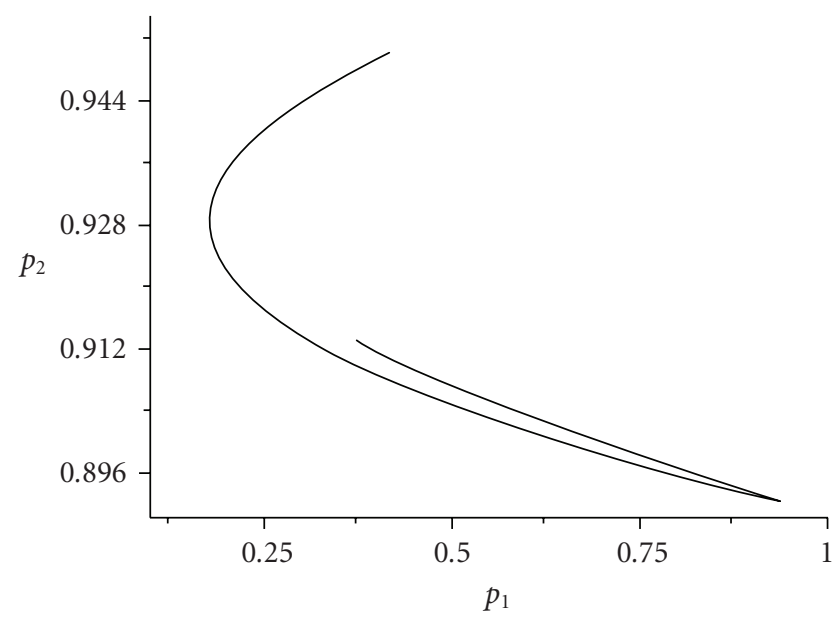

FIGURE 4.6. Strange attractor for $\alpha_{2}=0.2$.

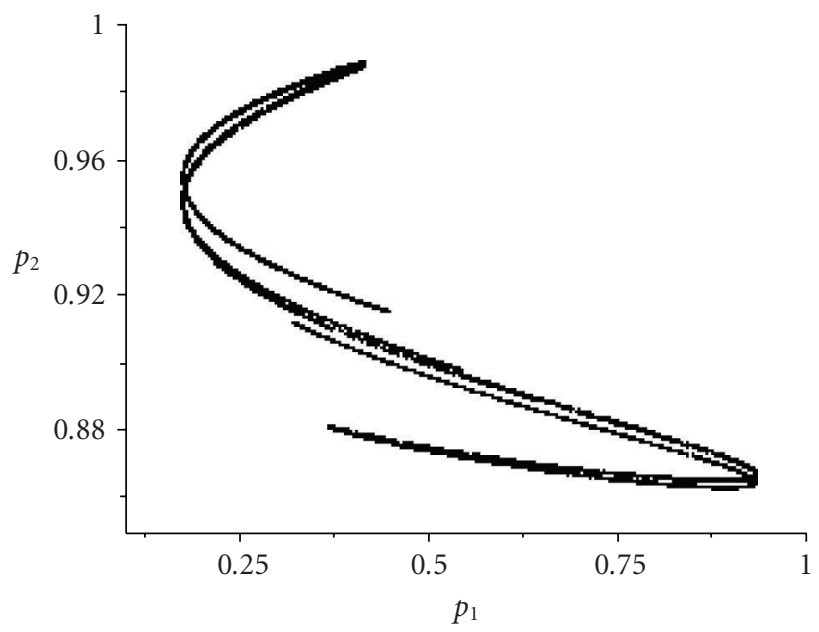

FIgURE 4.7. Strange attractor for $\alpha_{2}=0.3$.

value of $p_{1}(0)+0.0001 ; \Delta p_{2}(t)=p_{2}(t)-p_{2}^{\prime}(t)$, and $p_{2}^{\prime}(t)$ is the value of housing price at time period $t$ with initial value of $p_{2}(0)+0.0001$. In both figures, initial condition of one coordinate differs by 0.0001 , the other coordinate keeps equal. At the beginning, the difference is indistinguishable but after a number of iterations the difference between them builds up rapidly. From Figures 4.8 and 4.9, we show that the time series of the system (3.1) is sensitive dependence on initial conditions, that is, complex dynamics behaviors occur in this model. 


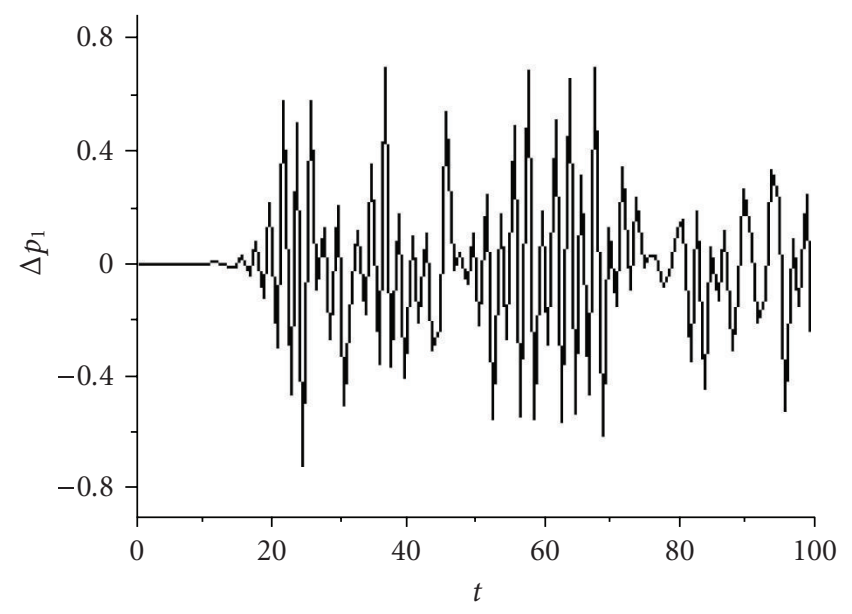

Figure 4.8. Sensitivity to initial conditions of $p_{1}$.

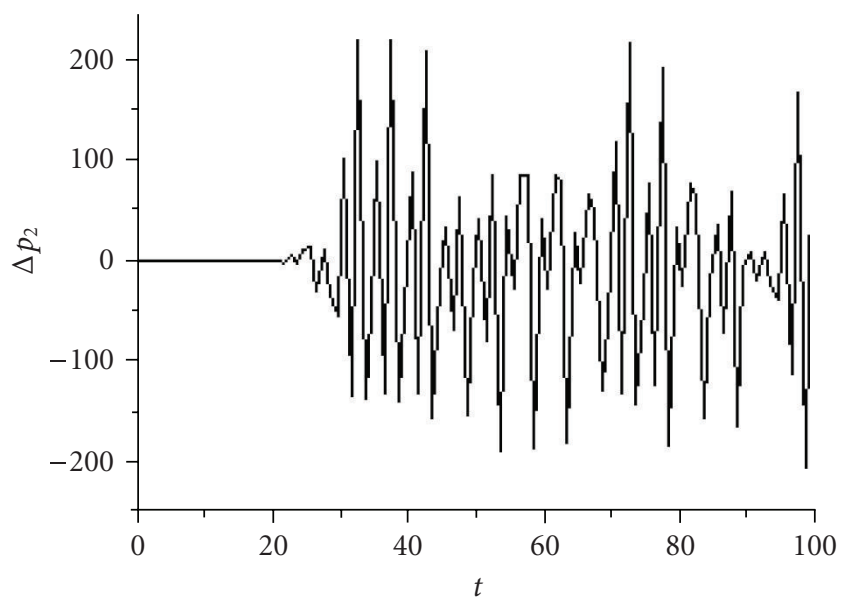

Figure 4.9. Sensitivity to initial conditions of $p_{2}$.

\section{Chaos control}

Delay feedback control (DFC) method was brought forward by Pyragas [16]. The method allows a noninvasive stabilization of unstable periodic orbits (UPOs) of dynamical systems [17]. It feeds back part of system output signals as exterior input to the system after a time delay. $u(\bullet)$ is control signal gained by self-feedback coupling between output and input signals in chaotic system. $x(t)=f(x(t-1))+u(t)$ is the form of DFC, where $u(t)=k(x(t)-x(t-\tau)), t>\tau, \tau$ is time delay, $k$ is controlling factor. Though delay feedback control is only carried out on one variable, it enables other variables in the system to achieve stability simultaneously. Our goal is to control the system in such way. The 


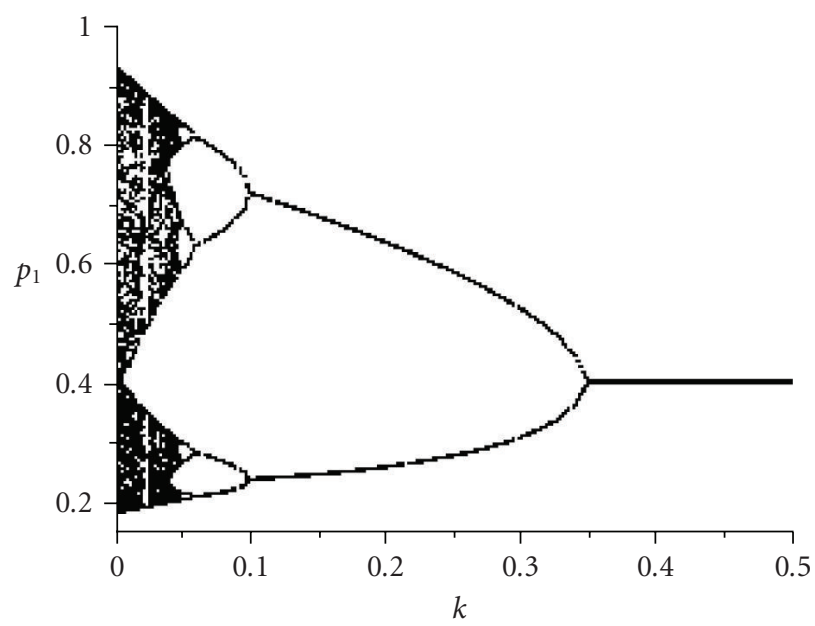

Figure 4.10. Relation graph of $p_{1}$ and $k$.

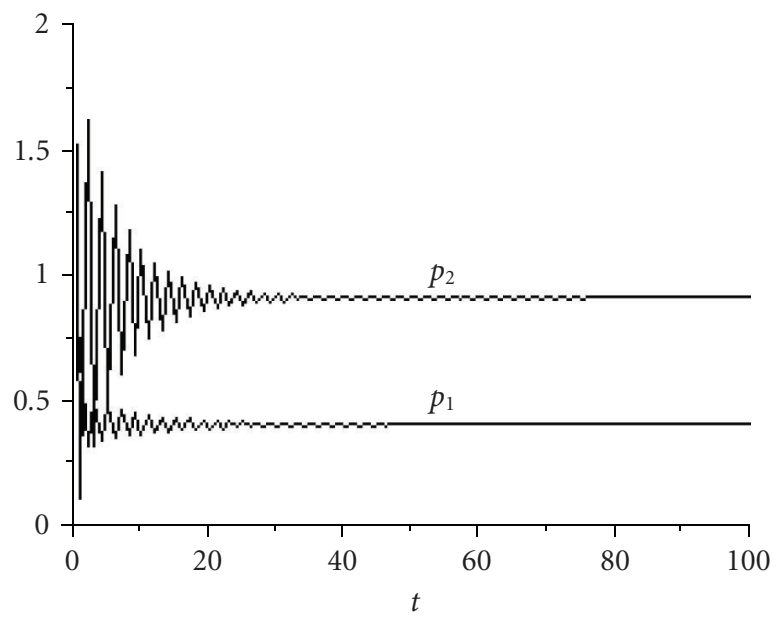

FIgURe 4.11. Time series of $p_{1}$ and $p_{2}$ with $k=0.4$.

system with controlling factor is shown as follows:

$$
\begin{aligned}
& p_{1}(t)=p_{1}(t-1)+\alpha_{1} Z\left(p_{1}(t-1)\right)-k\left(p_{1}(t)-p_{1}(t-\tau)\right), \\
& p_{2}(t)=p_{2}(t-1)+\alpha_{2} Z\left(p_{2}(t-1)\right),
\end{aligned} \quad t=0,1,2, \ldots .
$$

From Figure 3.1, we know that chaos exists in system (3.1) when $\alpha_{2}=0.4, \alpha_{1}=2.3$. Choosing $\tau=1$, first inspect the relation of $k$ and system stability. The Jacobian matrix of 
system (5.1) is

$J=\left[\begin{array}{cc}\left(1-\alpha_{1}\left(e_{1}+b_{1}\right)+k+2 \alpha_{1}\left(b_{2}-e_{2}\right) p_{1}(t)\right) /(1+k) & 0 \\ \alpha_{2} d_{3} & 1-\alpha_{2}\left(d_{1}+c_{1}\right)+2 \alpha_{2}\left(c_{2}-d_{2}\right) p_{2}(t)\end{array}\right]$.

Substituting equilibrium point $(0.4,0.9)$ into $(5.2)$, we obtain eigenvalues $\lambda_{1}=-0.83$, $\lambda_{2}=(k-1.7) /(1+k)$. So when $k>0.35$, absolute values of both eigenvalues are less than 1 , which means that the system is stable.

As shown in Figure 4.10 land price is controlled from chaotic state to stable state when $k$ is greater than 0.35 , so we select $k=0.4$. Housing price and land price are also controlled to equilibrium point $(0.4,0.9)$ as shown in Figure 4.11 .

\section{Conclusion}

A nonlinear model for real estate market has been presented based on the cobweb theory. It is a simple dynamic model with nonlinear demand and supply function. From numerical simulations, we deduce that the land supply system has the remarkable influence on real estate market. Therefore, policy makers who intervene in one market should recognize that what they do may also influence other relative markets. We showed that the fast adjustment cause a market structure to behave chaotically. Therefore, the dynamics of market is changed when players apply different adjustment speed. Attempts are also made to stabilize the chaotic system with the delay feedback method. Combining with this method, the land price and housing price evolve from chaotic to stable.

\section{Acknowledgments}

The authors are grateful to Professor Chen Yu-shu (Academician of Chinese Academy of Engineering) and Mrs. Liang Jiao-jie for their helpful comments. The authors thank three anonymous referees for their valuable suggestions and remarks. Any errors or shortcomings are our own.

\section{References}

[1] W. A. Brock and C. H. Hommes, "A rational route to randomness," Econometrica, vol. 65, no. 5, pp. 1059-1095, 1997.

[2] C. Chiarella, "The cobweb model, its instability and the onset of chaos," Economic Modeling, vol. 5, no. 4, pp. 377-384, 1988.

[3] B. Finkenstädt, Nonlinear Dynamics in Economics: A Theoretical and Statistical Approach to Agricultural Markets, Lecture Notes in Economics and Mathematical Systems no. 426, Springer, Berlin, Germany, 1995.

[4] C. H. Hommes, "Adaptive learning and roads to chaos: the case of the cobweb," Economics Letters, vol. 36, no. 2, pp. 127-132, 1991.

[5] C. H. Hommes, "Dynamics of the cobweb model with adaptive expectations and nonlinear supply and demand," Journal of Economic Behavior \& Organization, vol. 24, no. 3, pp. 315-335, 1994.

[6] R. V. Jensen and R. Urban, "Chaotic price behavior in a nonlinear cobweb model," Economics Letters, vol. 15, no. 3-4, pp. 235-240, 1984. 


\section{Discrete Dynamics in Nature and Society}

[7] A. Matsumoto, "Ergodic cobweb chaos," Discrete Dynamics in Nature and Society, vol. 1, no. 2, pp. 135-146, 1997.

[8] A. Matsumoto, "Preferable disequilibrium in a nonlinear cobweb economy," Annals of Operations Research, vol. 89, pp. 101-123, 1999.

[9] H. E. Nusse and C. H. Hommes, "Resolution of chaos with application to a modified Samuelson model," Journal of Economic Dynamics \& Control, vol. 14, no. 1, pp. 1-19, 1990.

[10] H. N. Agiza, A. S. Hegazi, and A. A. Elsadany, "Complex dynamics and synchronization of a duopoly game with bounded rationality," Mathematics and Computers in Simulation, vol. 58, no. 2, pp. 133-146, 2002.

[11] A. K. Naimzada and L. Sbragia, "Oligopoly games with nonlinear demand and cost functions: two boundedly rational adjustment processes," Chaos, Solitons \& Fractals, vol. 29, no. 3, pp. 707-722, 2006.

[12] T. Offerman, J. Potters, and J. Sonnemans, "Imitation and belief learning in an oligopoly experiment," Review of Economic Studies, vol. 69, no. 4, pp. 973-997, 2002.

[13] F. V. Waugh, "Cobweb models," Journal of Farm Economics, vol. 46, no. 4, pp. 732-750, 1964.

[14] T. Puu, Attractors, Bifurcations, and Chaos: Nonlinear Phenomena in Economics, Springer, Berlin, Germany, 2000.

[15] X. Li, G. Chen, Z. Chen, and Z. Yuan, “Chaotifying linear Elman networks," IEEE Transactions on Neural Networks, vol. 13, no. 5, pp. 1193-1199, 2002.

[16] K. Pyragas, "Continuous control of chaos by self-controlling feedback," Physics Letters A, vol. 170, no. 6, pp. 421-428, 1992.

[17] V. Pyragas and K. Pyragas, "Delayed feedback control of the Lorenz system: an analytical treatment at a subcritical Hopf bifurcation," Physical Review E, vol. 73, no. 3, Article ID 036215, 10 pages, 2006.

Junhai Ma: School of Management, Tianjin University, Tianjin 300072, China

Email address: mjhtju@yahoo.com.cn

Lingling Mu: School of Management, Tianjin University, Tianjin 300072, China

Email address: lingmu1020@163.com 


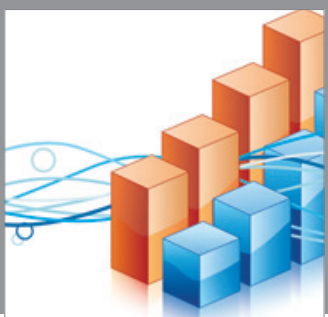

Advances in

Operations Research

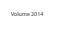

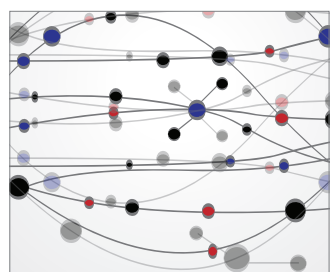

\section{The Scientific} World Journal
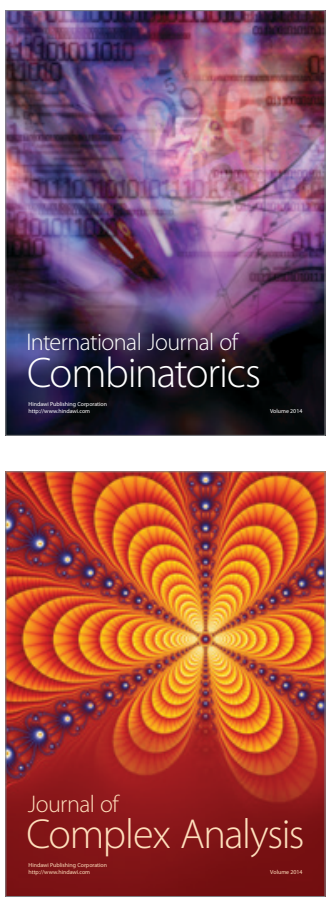

International Journal of

Mathematics and

Mathematical

Sciences
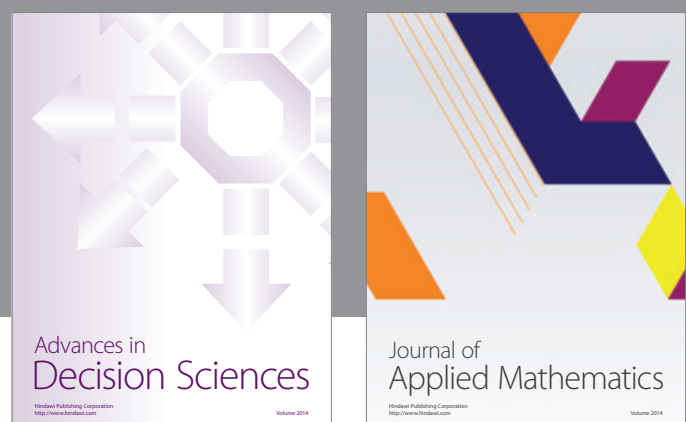

Journal of

Applied Mathematics
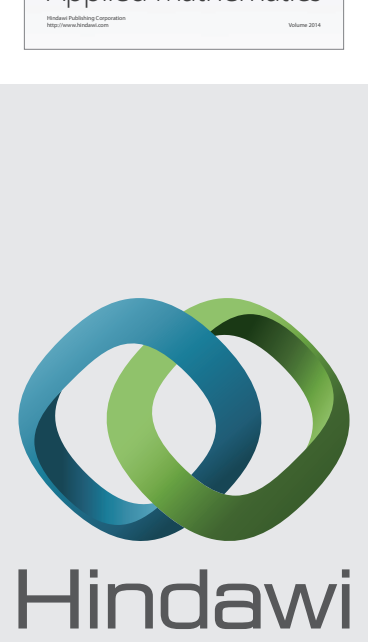

Submit your manuscripts at http://www.hindawi.com
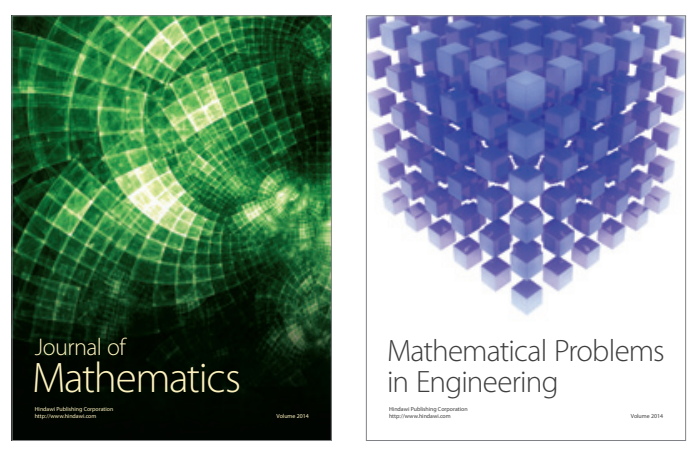

Mathematical Problems in Engineering
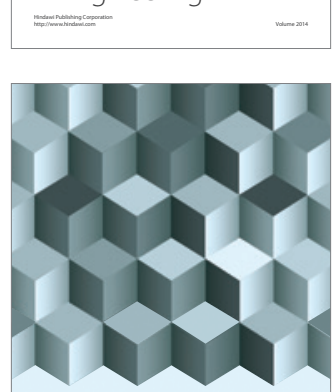

Journal of

Function Spaces
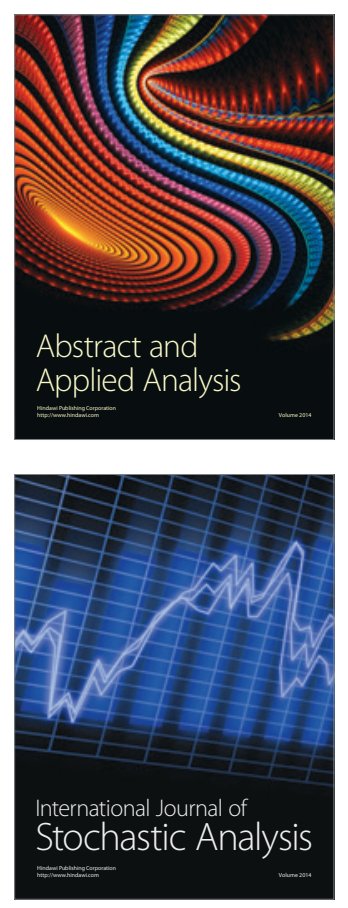

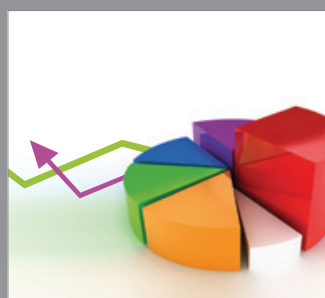

ournal of

Probability and Statistics

Promensencen
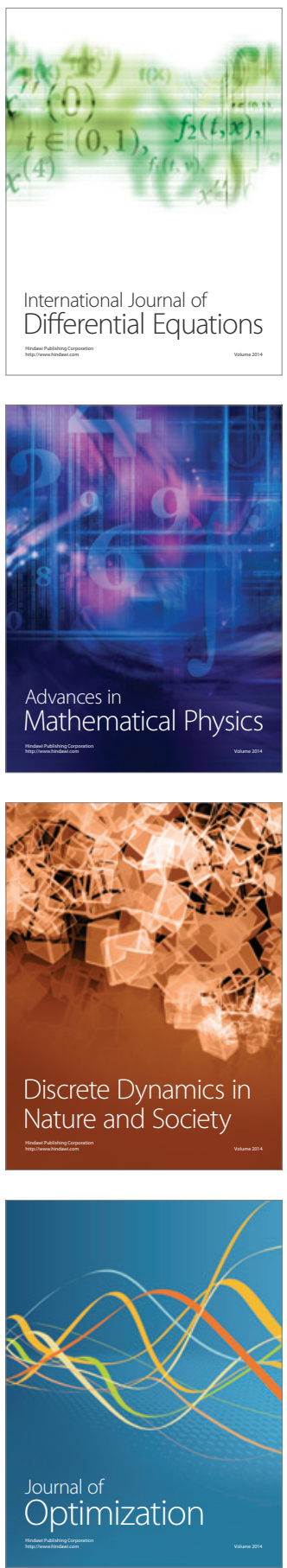